\title{
NOVAS FORMAS DE USO DO ESPAÇO DOMÉSTICO
}

\author{
COSTA FILHO, Lourival (1); \\ VILLACORTA, Juliana (2). \\ (1) Universidade Federal de Pernambuco | CAA | Doutor em Desenvolvimento Urbano \\ e-mail: lourivalcosta@yahoo.com \\ (2) Universidade Federal de Pernambuco | CAA | Designer \\ e-mail: julianavrm@gmail.com
}

\begin{abstract}
RESUMO
Este artigo abordou pernambucanos sobre o ambiente onde certas atividades domésticas ocorriam, tendo como objetivo identificar novas formas de uso do espaço doméstico. Para tal, foi realizada uma pesquisa exploratória on-line que apurou uma grande flexibilidade nos locais de ocorrência de diversas atividades e novas formas de uso do espaço doméstico.
\end{abstract}

Palavras-chave: espaço doméstico; atividades domésticas; ergonomia do ambiente construído.

\begin{abstract}
This article questioned people from Pernambuco about the environment where certain domestic activities occurred, aiming to identify new ways of using dwelling space. In order to do so, exploratory online research was carried out, which verified flexibility in the places where several activities were performed, and new forms of using dwelling space.
\end{abstract}

Keywords: dwelling space; domestic activities; ergonomics of the built environment.

\section{INTRODUÇÃO}

O ambiente construído se constitui no entorno da tarefa e influencia o ser humano no desempenho de suas atividades (MORAES, 2004).

Isso significa, apoiando-se na visão de Mont'Alvão (2011), que o ambiente construído é, em princípio, fruto da influência resultante das atividades humanas e que, posteriormente, vai influenciá-las.

Há, portanto, forte relação entre atividades e ambiente, a tal ponto que a ergonomia do ambiente construído, de acordo com Villarouco (2011), extrapolando questões puramente arquitetônicas, foca o seu posicionamento na adaptabilidade e conformidade do espaço às atividades que nele irão se desenvolver.

A partir do exposto, é possível afirmar que a relação entre as atividades e o ambiente construído é necessária dentro da abordagem ergonômica, cabendo ainda alertar que nenhum projeto para o ambiente construído estará perfeitamente adequado sem 0 conhecimento prévio, por parte do projetista, da sua real situação de uso. 


\section{(x) $^{\text {reac }}$}

Logo, se de um lado a ergonomia do ambiente construído permite adequar os espaços segundo as dimensões e os limites antropométricos dos usuários, o acesso e a articulação no manuseio de mobiliário, equipamentos e circulação da habitação, de outro, é igualmente necessário que se considerem as atividades realizadas no âmbito doméstico, bem como em quais ambientes elas estão distribuídas ou podem ser executadas (MACEDO, 2017).

Em razão disso, estudar os problemas relacionados às novas dinâmicas familiares parece ser um caminho para se produzir habitações com níveis satisfatórios de qualidade, mesmo que dentro de parâmetros dimensionais mínimos. Contudo, a maneira como as pessoas usam os ambientes habitacionais está intimamente ligada a fatores individuais, sociais e culturais que precisam ser conhecidos e levados em conta ainda na fase projetual.

As novas tendências comportamentais e as recentes transformações sociais, por exemplo, interferem diretamente no padrão espacial doméstico que, muitas vezes, tem sido descrito na literatura como sendo um espelho dessas alterações, das quais seria um reflexo (TRAMONTANO, 1996; VERRÍSSIMO; BITTAR, 1999; CÍRICO, 2001; BRANDÃO, 2002; CAMARGO, 2003; COSTA FILHO, 2005).

Nesse contexto, já é difícil imaginar o quarto apenas como um ambiente para o sono noturno, ou que a cozinha deva se manter isolada e "escondida" dos olhos dos visitantes, ou ainda que a mesa da sala de jantar seja usada estritamente para servir as refeições.

Ao abordar a forma de uso do espaço doméstico esta pesquisa busca contribuir com a elaboração de projetos de ambientes ergonomicamente mais adequados, bem como para o design de componentes fortemente relacionados, como o mobiliário e os equipamentos que irão compor os ambientes, uma vez que, projetar um produto habitacional adequado requer considerar onde e como as atividades ocorrem. Além disso, muitos projetistas ressentem-se de acesso a pesquisas sobre a satisfação do cliente em relação aos produtos adquiridos (COSTA FILHO, 2005), não desenvolveram o hábito de antever seus projetos em uso e/ou desconhecem o usuário final de seus projetos, principalmente quando se trata de edifícios habitacionais de uso multifamiliar, home services para aluguel no sistema long-stay, hotéis, casas de estudantes, entre outras tipologias habitacionais de uso compartilhado.

Para Panero e Zelnik (2002), a diversidade das atividades dentro dos espaços habitacionais é extraordinária. Independente de tipo e tamanho, são espaços onde as pessoas dormem, relaxam, alimentam-se, meditam, descansam, fazem serviços domésticos, leem, cozinham, são concebidas e até nascem ou morrem. Também é o local onde passam, pelo menos, metade de seu tempo quando acordadas, e estão sujeitas à maior parte de ferimentos que sofrem durante toda a sua vida. A quantidade e a variedade de funções produzidas, o tempo envolvido e a vulnerabilidade a situações de fadiga e acidentes, para os autores, denotam significação extra à qualidade da interface entre humanos, atividades e tais ambientes.

A partir das questões expostas, a pesquisa aqui apresentada questionou pernambucanos sobre os ambientes onde certas atividades domésticas eram realizadas, tendo como objetivo identificar novas formas de uso do espaço doméstico nos tempos atuais.

\section{CONSIDERAÇÕES TEÓRICAS}

\subsection{Formas Tradicionais de Uso dos Principais Ambientes Domésticos}

Quando se observa a produção de projetos do uso habitacional, em todos os casos do programa de necessidades, mais simples ou mais complexo, mais reduzido ou mais amplo, 


\section{(x) $^{\text {reac }}$}

invariavelmente, eles apresentam a concepção tripartite da moradia, em setores social, íntimo e de serviços (ARAÚJO, 2003).

Para suprir as diferentes necessidades humanas como conviver, cuidar do corpo, armazenar, limpar entre outras, a habitação sintetiza diferentes funções domésticas. Uma leitura comparada entre os autores deste tema aponta que a maiorias das funções é comum a todos, sendo elas: a) convívio familiar e social, lazer e recreação; b) alimentação; c) repouso; d) estudo e trabalho; e) higiene pessoal; f) tratamento de roupas; g) manutenção doméstica e armazenagem; h) circulação e estacionamento de veículos (MACEDO, 2017).

Tais funções, por sua vez, podem ser desdobradas segundo grupos de atividades principais. Assim, apesar de não estarem restritas exclusivamente a um determinado cômodo, para Macedo (2017), no caso brasileiro, o convívio familiar, social, lazer e recreação está nas salas de estar e jantar, a alimentação está dividida entre a cozinha e a sala de jantar, as funções de repouso estão normalmente associada aos dormitórios, o estudo e o trabalho podem estar nas salas, em cômodos específicos ou dividir lugar nos dormitórios, a higiene pessoal acontece geralmente nos banheiros, podendo algumas atividades serem redistribuídas para os dormitórios e o tratamento de roupa localiza-se em geral na área de serviços. As funções de manutenção doméstica, armazenagem e circulação devem ser consideradas em todos os ambientes, enquanto o estacionamento encontra-se na garagem.

No setor social, as atividades de convívio familiar, social e lazer muitas vezes são atividades de natureza coletiva, tais como: fazer refeições coletivamente, receber visitas, conversar, assistir televisão, ouvir música, ler, brincar, jogar, realizar atividades manuais e usar o computador - cada vez mais presente nas residências. O centro do setor social e seu principal ambiente é a sala de estar, ainda que agregada, com o correr do tempo, a sala de jantar. Segundo Veríssimo e Bittar (1999), a partir do fim do século XX, em muitas ocasiões, o receber passou a ser realizado exteriormente à própria residência, nas áreas comuns dos condomínios ou em espaços específicos locados para essa finalidade.

O setor íntimo, contemplando principalmente quartos e banheiros, geralmente remete ao isolamento, para proporcionar privacidade aos seus usuários. O quarto, principal cômodo deste setor, sempre abrigou funções de repouso, sono, sexo e, mais recentemente, de convívio social. As atividades inerentes a função de repouso e sono são: dormir, descansar, ler, convalescer, tratar enfermos, alojar hóspedes, cuidar de crianças, permanecer reservado. No Brasil, esse setor só veio a apresentar mudanças significativas no século XIX, atendendo às novas demandas de comportamento. Na década de 1960, começou a se configurar as suítes, anexando banheiros privativos aos quartos para atender a função de higiene pessoal, que abrange as necessidades de higiene corporal e corresponde as atividades de tomar banho, lavar mãos e rosto, vestir-se e despir-se, escovar os dentes, fazer a barba e pentear os cabelos, atender as necessidades fisiológicas. Nos dias atuais, novas funções foram agregadas, já que além de receber, o usuário, dependendo de sua faixa etária, precisa estudar, realizar tarefas escolares, trabalhar em casa e usar o computador ou telefone, além de armazenar tudo que está agregado a essas atividades. Hoje se percebe a extrema individualização do uso de um quarto, onde o usuário pode ainda possuir TV privativa e, em alguns casos, geladeira individual e aparelhos de ginástica.

O setor de serviços, englobando cozinha e lavanderia, é destinado às funções de alimentação e tratamento de roupas. As principais atividades relacionadas à alimentação são: guardar alimentos e utensílios, preparar alimentos e refeições, lavar utensílios, eliminar resíduos, enquanto as atividades relativas ao consumo de alimentos correspondem a fazer refeições correntes ou formais. A função de tratamento de roupas compõe-se de atividades de naturezas distintas, tais como: armazenar roupa suja, lavar roupa a mão ou na máquina, secar roupa, costurar roupa, passar roupa e guardar roupa limpa. Com a chegada da energia, os aparelhos elétricos foram instalados, introduzindo uma tendência às alterações físicas, principalmente no sentido da diminuição dos espaços domésticos, pois as casas 


\section{(x) $^{\text {reac }}$}

menores eram mais fáceis de limpar. A cozinha é seu principal ambiente. Tem-se também a copa, apesar da sua diminuição e, por vezes, extinção, ainda hoje persiste, principalmente nas casas grandes e abastadas, como local de refeições rápidas, área de preparo final de alimento e guarda de acessórios para o serviço da sala de jantar. Nele pode estar inserida a dependência de empregados, ocorrência curiosa, mantida até hoje, apenas no Brasil.

\subsection{Transformações Comportamentais e dos Espaços de Morar}

Nas últimas décadas, novas tendências comportamentais têm sido percebidas, com muita clareza, em todo o mundo ocidentalizado, principalmente em meio urbano, metropolitano ou sob influência cultural metropolitana, via meios de comunicação a distância. Por trás desse processo estão, principalmente, a liberação da mulher e sua inserção no mercado de trabalho, o aparecimento de novos formatos familiares e novos modos de vida, incluindo o trabalho em casa - eventualmente plugado a uma rede de transmissão de informações -, o culto ao próprio corpo, as preocupações de caráter ambiental, o super-equipamento do espaço doméstico, a demanda por espaços públicos protegidos, onde possam encontrar-se indivíduos de uma sociedade que compõe-se cada vez mais por solteiros, descasados, viúvas, ou, no máximo, casais sem filhos (TRAMONTANO, 1996; CAMARGO, 2003).

Essas novas tendências comportamentais, relacionadas com recentes transformações sociais, interferem no padrão de morar e na forma de uso dos espaços domésticos. Para abordar cada elemento motivador dessas mudanças, seguem-se os próximos parágrafos, que destacam os novos arranjos familiares, o papel da mulher, o home office, o processo de acúmulo de eletroeletrônicos e a compactação da moradia.

A nuclearização da unidade familiar sofreu alterações potencializadas na segunda metade do século $X X$, quando surgem novos formatos, como famílias monoparentais, casais sem filhos, uniões livres - incluindo casais homossexuais -, grupos coabitando sem laços conjugais ou de parentesco entre seus membros, e novo formato de família nuclear, ainda dominante nas estatísticas, em que se percebe redução do controle patriarcal e sentido de independência individual (TRAMONTANO, 1996; CAMARGO, 2003; BRANDÃO, 2003). As separações, por exemplo, multiplicaram o número de grupos domésticos, diminuíram o tamanho médio da família e aumentaram a demanda por habitação; o cônjuge que passa a morar sozinho irá necessitar de espaço para receber os filhos; a nova família nuclear, composta de casais com filhos de uniões anteriores e, às vezes, com outros novos, necessita de espaços na habitação que propicie a preservação das individualidades de seus membros, suas atribuições e mesmo dos novos hábitos (COSTA FILHO, 2005).

$O$ ingresso da mulher em parcelas do mercado de trabalho, antes reservadas ao homem, trouxe forte impacto na estrutura e composição da família e na distribuição de papéis dentro dela. As mulheres autônomas financeiramente, com nível de instrução mais elevado, declaram-se insatisfeitas com seus casamentos, autonomia que requer uma redefinição de papéis dentro e fora da família (TRAMONTANO, 1996), além de repercutirem no interior doméstico; nos espaços, nos equipamentos e também nos materiais de acabamento (BRANDÃO, 2002; COSTA FILHO, 2005).

Algumas condições facilitaram a introdução do trabalho em casa, como a revolução da informática, que permitiu a comunicação virtual rápida e segura, transportando informações de forma ágil e fácil; o surgimento de profissões que permitem a escolha do lugar e horário independentes, sem prejuízo de desempenho, e a própria condição das grandes cidades, que dificulta os deslocamentos e provoca grandes desgastes físico-emocionais nas pessoas. (TRAMONTANO, 2004). Essa questão vem sendo tratada como uma transformação socioeconômica contemporânea, que implica uma crescente mutação do espaço da moradia e da demanda por habitações personalizadas (CAMARGO, 2003). 


\section{(x) $^{\text {reac }}$}

A estabilidade monetária alcançada a partir de meados dos anos 1990 , juntamente com o aumento real do poder aquisitivo das classes médias e populares brasileiras, trouxe grande euforia consumista, refletida de modo particularmente acentuado no interior das moradias (CAMARGO, 2003). A grande variedade na oferta de mobiliário, equipamentos e eletrodomésticos, nas últimas décadas, e mais recentemente, as novas mídias, representadas pelos sistemas televisivos a cabo e via satélite, sistema de telefonia celular e Internet, certamente promovem impactos no interior doméstico, sugerindo mudanças na forma de uso dos espaços habitacionais (COSTA FILHO, 2005). Nesse contexto, o ambiente doméstico brasileiro rapidamente incorporou opções de entretenimento eletrônico, integrando-se à tendência mundial de substituir pelo prazer doméstico, a diversão na rua.

Outro fator relevante que impacta nos espaços habitacionais é a compactação da moradia. A partir da segunda metade dos anos 1960, num processo que se estende até os dias atuais, o grande adensamento populacional e os altos preços do solo deram início à produção em série de apartamentos habitacionais, cuja arquitetura passou à gradativa desconsideração das necessidades humanas (CAMARGO, 2003).

\section{CONSIDERAÇÕES METODOLÓGICAS}

O objeto de estudo desta pesquisa situa-se na relação entre as atividades e os ambientes domésticos, ou seja, a forma de uso do espaço doméstico.

Quanto à população amostral, levou-se em conta pernambucanos economicamente ativos, maiores de idade e residentes em casa ou apartamento. Definida a população, foi realizada uma pesquisa de campo do tipo exploratória (MARCONI; LAKATOS, 2004), que optou pelo questionário on-line, com perguntas fechadas - divulgado nas Redes Sociais e utilizando a plataforma Google para transmissão na Internet -, como instrumento de coleta de dados.

O objetivo da pesquisa: abordar pernambucanos sobre os ambientes onde certas atividades domésticas ocorrem, visando identificar novas formas de uso do espaço doméstico, norteou o desenho da investigação e, principalmente, do instrumento de coleta de dados.

Nessa linha, optou-se pelo uso do questionário, elaborado com 16 questões que, para facilitar sua estruturação, posterior análise e discussão dos resultados, foi dividido em três partes: 1| dados pessoais; 2| questões exploratórias sobre o tipo de residência; $3 \mid$ questões exploratórias sobre as atividades desempenhadas nos ambientes.

Os dados pessoais relacionaram-se com sexo, idade, nível de escolaridade, renda familiar dos participantes e se algum morador exercia alguma atividade produtiva em tempo integral ou parcial - em casa - a fim de compreender o perfil da amostra.

As questões exploratórias referentes ao tipo de residência sondaram os participantes sobre a tipologia da moradia (casa/apartamento), se é própria ou alugada, o número de ocupantes, o número de cômodos, se algum quarto era compartilhado, e sobre os eletroeletrônicos existentes, a fim de caracterizar o padrão das habitações enfocadas.

As questões exploratórias sobre as atividades desempenhadas nos ambientes, diretamente relacionadas com o objetivo da pesquisa, abordaram os participantes sobre o ambiente doméstico onde certas atividades, como: receber visitas; assistir à TV, a filmes, ouvir músicas e jogar; fazer refeições longas e rápidas; ler, estudar, desenvolver trabalhos intelectuais; realizar exercícios físicos; e outras mais que poderiam ser citadas por eles, eram desempenhadas, a fim de identificar novas formas de uso do espaço doméstico, para contribuir com referências para o projeto desse tipo de espaço, e ainda de outros elementos fortemente relacionados, como o design de mobiliário, de equipamentos e o arranjo físico destes componentes nos ambientes. 


\section{(x) $^{\text {reac }}$}

Definido o instrumento de coleta dos dados, aplicaram-se pré-testes que envolveram três voluntários, para definir a versão final das questões. As alterações sugeridas foram poucas e incorporadas ao questionário. Os dados coletados nessa fase foram desprezados, pois a configuração de algumas questões precisou ser alterada.

Por se tratar de uma pesquisa exploratória, inicialmente não foi estabelecido um número exato para a amostragem, uma vez que essa seria de caráter não realístico/probabilístico. No final do prazo estabelecido, ao todo, foram respondidos 258 questionários.

Os dados coletados foram automaticamente processados e tabulados pelo próprio sistema de questionários on-line utilizado; a planilha completa de respostas foi impressa e as análises dos principais achados serão apresentadas e discutidas, conjuntamente, a seguir.

\section{PRINCIPAIS RESULTADOS ENCONTRADOS}

\subsection{Dados dos Usuários}

A população amostral de 258 pessoas era formada por 159 mulheres $(61,63 \%)$ e 99 homens $(38,37 \%)$. A maioria na faixa etária de 18 a 29 anos (91 pessoas), ensino superior incompleto (141 pessoas) e renda familiar mensal de 5 a 15 salários mínimos (80 pessoas), acompanhada de perto pela faixa de 3 a 5 salários mínimos (77 pessoas), que os situam, segundo definição do IBGE, nas classes sociais B e C. A classe B, segundo matéria do Jornal Estado de S. Paulo, é ávida por consumo e quer requinte. Já a classe $\mathrm{C}$, de acordo com reportagem do portal EXAME.com, é chamada de "nova classe média", e passou a englobar mais da metade dos brasileiros; predominantemente jovem e composta, em sua maioria, por afrodescendentes.

Cabe destacar que 76 participantes responderam exercer alguma atividade produtiva em casa $(29,45 \%)$, sendo a atividade de freelancer, sem especificar a natureza do trabalho, a única descrita nas respostas. Como a maioria da população participante é predominantemente formada por jovens (faixa etária de 18 a 29 anos) e possui ensino superior incompleto, conforme foi acima descrito, imagina-se que muitas dessas ocorrências estejam relacionadas com atividades produtivas realizados por estudantes universitários, em tempo parcial. Logo, a tendência do trabalhar em casa, antecipada nas considerações teóricas, foi confirmada nas evidências empíricas desta pesquisa, sendo o quarto, o principal protagonista para o desenvolvimento dessa atividade.

\subsection{Questões Exploratórias sobre a Residência}

Quanto à tipologia habitacional, 153 respondentes (59,30\%) moram em apartamentos e 105 (40,69\%) em residências unifamiliares (casas).

Foi interessante observar o expressivo número de casas, ainda que a maioria resida em apartamentos, na medida em que, apoiando-se em Loureiro e Amorim (2002), atualmente, a violência urbana é um fator preponderante para transformar o apartamento na expressão máxima das novas formas de habitar. A residência unifamiliar, símbolo de status é o grande sonho de consumo da família moderna, que parece hoje incapaz de manter o seu poder de atração, por não concretizar a imagem do lar como refúgio seguro da família.

Cabe salientar que as áreas privativas dos apartamentos, cada vez mais compactas, vêm se caracterizado pela diminuição em tamanho, e que podem impactar negativamente o 
desempenho das atividades habitacionais, a alocação e a distribuição do mobiliário dentro dos ambientes e até o modo de morar de quem os ocupa.

Das 258 moradias, também se apurou que 182 delas são próprias (70,54\%), 70 alugadas $(27,13 \% \%)$ e $6(2,32 \%)$ emprestadas. Esse representativo número de moradias próprias talvez seja decorrente de recentes iniciativas do governo federal que encorajaram a política de financiamento da casa própria à população.

Quanto ao número de pessoas, 77 habitações são ocupadas por 4 pessoas $(29,84 \%), 70$ por 3 pessoas (27,13\%), 36 por 2 pessoas (13,95\%), 12 por uma única $(4,65 \%)$, entre outros números menos expressivos. Como a maioria da população respondente estava situada na faixa etária de 18 a 29 anos, jovens em início de sua formação universitária ou carreira profissional, presume-se que ainda morem com os pais.

Em relação ao número de cômodos internos, a maioria respondeu nove -2 salas $(48,83 \%)$, 3 quartos (42,63\%), 2 banheiros (35,65\%), cozinha e área de serviços. Não houve citação dos corredores, geralmente tomados mais como espaços transitórios de conexões que ambientes ou cômodos domésticos propriamente ditos.

Em 182 das moradias, nenhum quarto é compartilhado (70,54\%). Tal compartilhamento, inclusive entre cônjuges, ocorreu em apenas 74 delas (28,68\%), talvez expressando uma consideração teórica apresentada, que alertava para uma sociedade que parece tender a compor-se cada vez mais por solteiros, descasados, viúvas, ou, no máximo, casais sem filhos. Brandão (2003) e Camargo (2003) descrevem, a partir da demógrafa Elza Berquó, a queda acentuada da taxa de fecundidade, a fragilidade cada vez maior das uniões e o individualismo acentuado como tendências que vêm atuando no sentido de alterar o tamanho, a estrutura e a função da família nuclear.

Foi também perguntado sobre a existência e o número de aparelhos eletroeletrônicos (TV, DVD, aparelho de som, computador, micro-ondas, frigobar, aparelhos de ginástica) nas moradias, Entre todos, o computador foi o único que estava presente em todas as habitações, sendo que em 70 delas há 1 computador (27,13\%), em 60 há $3(23,25 \%)$ e em 53 há $4(20,54 \%)$. Na maioria delas, há 2 TVs (31,00\%), 1 DVD (48,06\%), 1 aparelho de som (17,82\%), 2 computadores (28,68\%) e 1 micro-ondas (79,06\%). Frigobar e aparelhos de ginástica, empatados, estavam presentes em $14,72 \%$ do total de moradias. Fogão e geladeira foram tomados como itens básicos, presente na maioria das moradias, sendo desconsiderados entre os produtos listados.

O uso do computador, consagrado em multifinalidade, parece ter se tornado hoje, conforme apontado nas considerações teóricas, essencial para toda a família. Na mesma direção, o conforto doméstico foi muito favorecido com o surgimento e a facilidade de aquisição de uma diversidade de produtos para o lar, pois otimizaram as tarefas e atividades realizadas em casa. Além do mais, trouxeram para dentro da habitação contemporânea a possibilidade não só do trabalho, mas também, de informações, serviços e entretenimento, que certamente promovem impactos, sugerindo mudanças no desenho do espaço habitacional. Outro impacto direto, principalmente relacionado às novas mídias - representadas pelos sistemas televisivos a cabo e via satélite, sistema de telefonia celular e Internet - está no crescente tempo de permanência da família no espaço doméstico, motivado pela possibilidade de executar tarefas antes só possíveis com um deslocamento físico.

\subsection{Questões Exploratórias sobre as Atividades Desempenhadas nos Ambientes Domésticos}

Neste bloco, os participantes foram solicitados a indicar os ambientes de sua moradia onde realizavam certas atividades domésticas. Dos 258 respondentes, 184 declararam receber na 


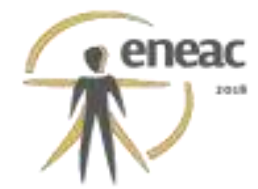

sala de estar (71,31\%), 32 no quarto (12,40\%), 14 na cozinha (5,42\%), 10 na sala de jantar $(3,87 \%)$ e 18 marcaram outros $(6,97 \%)$. No desdobramento da última questão, 13 recebem no terraço ou na varanda $(5,03 \%)$ e 5 citaram mais de um ambiente $(1,55 \%)$. (Figura 1$)$

Figura 1: distribuição da atividade de receber visitas

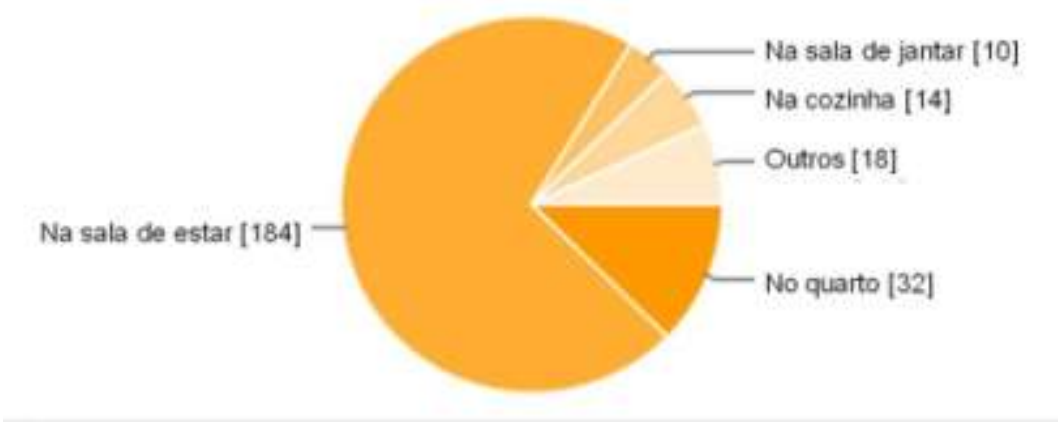

Fonte: autores baseados nos resultados da pesquisa

Conforme apresentado nas considerações teóricas, o receber sempre foi uma atividade característica do setor social e, principalmente, da sala de estar. Assim, as evidências empíricas reforçaram o hábito, embora revele que o quarto também incorpora essa função, revelando-se como espaço de socialização, menos isolado que outrora. Note-se, entretanto, que o receber aparece muito desvinculado da sala de jantar, indicativo que a atividade parece dissociada das refeições.

Quanto às atividades de recreação e lazer, como assistir à TV, a filmes, ouvir músicas, 146 deles responderam na sala de estar $(56,58 \%), 95$ no quarto $(36,82 \%)$, 3 na sala de jantar $(1,16 \%), 1$ na cozinha $(0,38 \%)$ e 13 citaram outros $(5,03 \%)$. Desdobrando-se o último item, 9 declararam na sala de TV (3,48\%) e 4 não haver um ambiente específico (1,55\%). (Figura 2$)$

Figura 2: distribuição das atividades de assistir à TV, a filmes, ouvir música

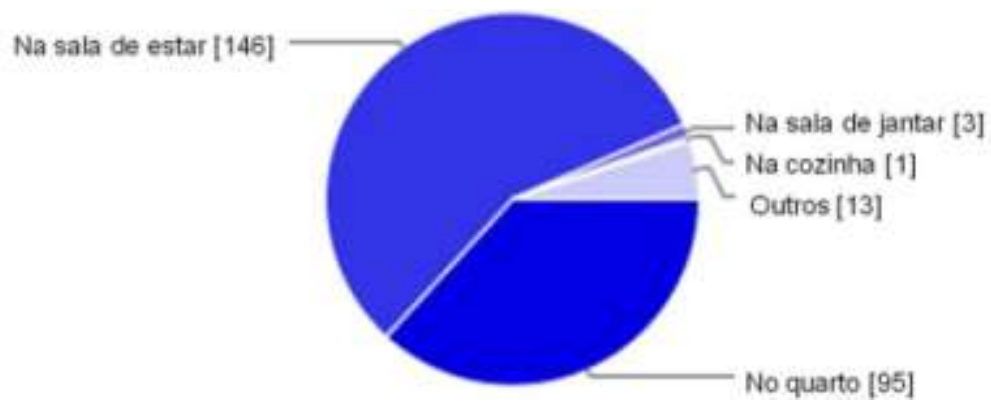

Fonte: autores baseados nos resultados da pesquisa

Mais uma vez, confirma-se a tradição da sala de estar como espaço de natureza coletiva e convívio familiar. Também não causa estranhamento o fato de o quarto ser uma opção secundária, na medida em que esse ambiente, hoje, abriga aparelhos relacionados com a ocorrência dessas atividades de recreação e lazer. 


\section{(x) $^{\text {reac }}$}

Em relação às refeições longas ou rápidas, 102 participantes responderam na cozinha $(39,53 \%), 65$ na sala de jantar $(25,19 \%), 55$ na sala de estar $(21,31 \%), 25$ no quarto $(9,68 \%)$ e 11 em outros $(4,26 \%)$, tais como: na sala de TV $(3,10 \%)$ e fora de casa $(1,16 \%)$. (Figura 3$)$

Figura 3: distribuição das atividades de assistir à TV, a filmes, ouvir música

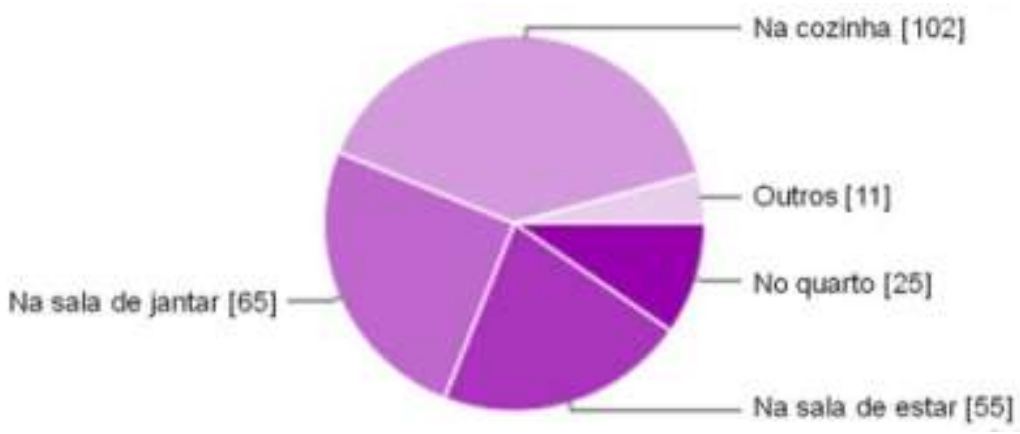

Fonte: autores baseados nos resultados da pesquisa

Esse tipo de atividade apurou um dado inusitado, que revela novas formas de uso dos ambientes habitacionais, - o comer realizado predominantemente na cozinha, pelos participantes desta pesquisa -, bem como flexibilidade na ocorrência dessa atividade, com números expressivos também na sala de estar e no quarto. As refeições tradicionalmente ocorriam na sala de jantar, na copa ou mesmo, após influência americana e obsessão pela racionalização do espaço, na parte da sala única, reservada para essa função, ambientes onde os problemas do cotidiano familiar eram resolvidos em torno da mesa, na presença de todos. Com a sedimentação de alguns hábitos, como a "eletromodernização" da cozinha, cada membro da família passou a fazer refeição em um horário, acordar mais cedo ou mais tarde, não almoçar ou jantar em casa como antes. A alteração de ambiente protagonista para as refeições, da sala de jantar para a cozinha, indica que as refeições estão sendo realizadas de forma individualizada. Cabe destacar, todavia, que as cozinhas de muitos novos apartamentos estão relegadas a um mero depositário de aparelhos de última geração para preparo de alimentos pré-prontos ou congelados, e somente em alguns conseguem-se inserir mesa ou mesmo bancada na altura de mesa que apoiem as refeições.

Quanto ao ambiente para ler, estudar e realizar outros trabalhos intelectuais, foi apurado que 190 sujeitos responderam no quarto (73,6\%), 35 na sala de estar (13,56\%), 9 na sala de jantar (3,48\%), 5 na cozinha (1,93\%) e 19 marcaram outros $(7,36 \%)$. Nesse caso, 0 desdobramento da pergunta apontou 15 no home office $(5,81 \%), 3$ na área externa $(1,16 \%)$ e 1 no corredor (0,38\%). (Figura 4$)$

Esses achados ratificam que, além das atividades tradicionais e inversamente à redução do espaço físico nas moradias da classe média, o quarto incorporou novas funções, onde o computador é a principal ferramenta de quem, em tempo de Internet, não precisa sair de casa sequer para fazer compras. Salienta-se, contudo, que ambientes como sala de estar, sala de jantar e até a cozinha também foram citados, revelando flexibilidade na ocorrência dessas atividades no espaço doméstico.

Com relação à prática de exercícios físicos, 213 sujeitos responderam negativamente. Dos que afirmaram de modo positivo, 24 os fazem no quarto $(9,30 \%)$, 8 na sala de estar $(4,05 \%)$ e 13 citaram outros $(5,03 \%)$ como terraço, varanda ou área externa.

Mais uma vez o quarto aparece nesta pesquisa como protagonista da prática de exercícios físicos, causando certo estranhamento e fazendo supor que pode se tratar apenas do uso 


\section{(x) $^{\text {reac }}$}

de certos aparelhos de fisiculturismo, como esteiras, bicicletas ou outros mais simples e menores, mais facilmente adaptáveis ao interior do quarto.

Figura 4: distribuição das atividades de ler, estudar, e outros trabalhos intelectuais

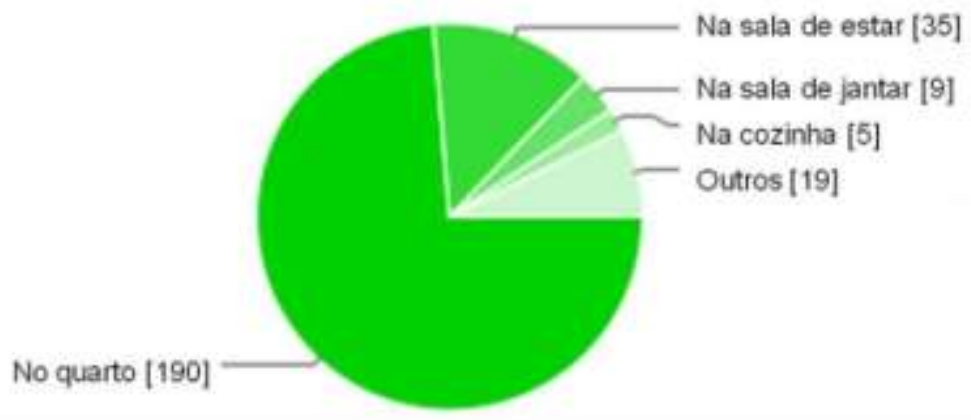

Fonte: autores baseados nos resultados da pesquisa

Perguntados se realizavam outras atividades domésticas além das que foram destacadas no questionário, 170 responderam negativamente (65,89\%), e 88 de modo afirmativo (34,10\%). Desses 88 participantes, 53 realizavam atividades manuais (pintar, desenhar, costurar) e 35 realizavam atividades musicais (tocar violão, guitarra, trompete ou ensaiar com banda). Quanto ao ambiente protagonista dessas atividades, 60 responderam no quarto, e 13 na sala de estar. Os demais citaram realizá-las em ambiente específico.

Fica confirmado que o quarto se revelou como protagonista do maior número de diferentes atividades domésticas, sendo lugar prioritário para ler, estudar, realizar outros trabalhos intelectuais, prática de exercícios físicos, atividades manuais, mas também é lugar para receber, assistir à TV, a filmes e ouvir músicas e fazer refeições, demonstrando que a tendência ao isolamento e ao individualismo entre moradores vem se confirmando.

\section{CONCLUSÃO}

O estudo da relação entre as atividades e os ambientes físicos é necessária na abordagem ergonômica. Desta forma, este artigo trouxe os principais resultados de uma pesquisa que questionou pernambucanos sobre o ambiente onde certas atividades domésticas ocorriam, com o objetivo de identificar novas formas de uso do espaço doméstico, visando contribuir com informações para a melhoria do projeto habitacional.

Respondendo às questões formuladas, que confirmaram algumas tendências expostas nas considerações teóricas, foi apurado que quase $30 \%$ dos respondentes exercem atividades produtivas na própria residência, em sua maioria apartamento, próprio, com nove cômodos, quatro pessoas, e, desconsiderando fogão e geladeira, reúnem dois computadores e duas TVs, bem como um DVD, um micro-ondas, um aparelho de som, e com frigobar e aparelhos de ginástica, igualmente empatados, presentes apenas em $14,72 \%$ dessas moradias. $O$ computador, entretanto, foi o único equipamento presente em todas as moradias.

Respondendo agora às questões mais diretamente ligadas ao objetivo formulado, identificar novas formas de uso do espaço habitacional, apurou-se que o receber permanece se dando principalmente na sala de estar, assim como assistir à TV, a filmes e ouvir música. Já em relação às refeições, foi interessante notar que a sala de jantar perdeu sua condição de protagonista para a cozinha, da mesma forma que ler, estudar, desenvolver outros trabalhos 


\section{(x) $^{\text {remax }}$}

intelectuais, realizar atividades manuais e a prática exercícios físicos foram agora incorporadas àquelas tradicionais de descanso, sono e sexo do quarto, ambiente doméstico que, embora de forma secundária, é ainda lugar de receber e fazer refeições.

\section{REFERÊNCIAS}

ARAÚJO, Anete Regis Castro de. Espaço privado moderno e relações sociais de gênero em Salvador: 1930-1949. 2003. 327f. Tese (Doutorado) - Faculdade de Arquitetura, Universidade Federal da Bahia, Salvador, 2003.

BRANDÃO, Douglas Q. Diversidade e potencial de flexibilidade de arranjos espaciais de apartamentos: uma análise do produto imobiliário no Brasil. 2002. 429f. Tese (Doutorado), Programa de Pós-Graduação em Engenharia de Produção, Universidade Federal de Santa Catarina, Florianópolis, 2002.

CAMARGO, Érica Nogueira de. Desenho e uso do espaço habitável do apartamento metropolitano na virada do século 21: um olhar sobre o tipo "dois - dormitórios" na cidade de São Paulo. 2003. Dissertação (Mestrado) - Faculdade de Arquitetura e Urbanismo, Universidade de São Paulo, São Paulo, 2003.

COSTA FILHO, Lourival Lopes. Discussão sobre a definição dimensional em apartamentos: contribuição à ergonomia do ambiente construído. 2005. Dissertação (Mestrado) - Programa de PósGraduação em Design, Universidade Federal de Pernambuco. Recife, 2005.

MARCONI, Marina A.; LAKATOS, Eva Maria. Metodologia Científica. São Paulo: Atlas, 2004.

MACEDO, Priscila Ferreira de. Habitação mínima em Natal (RN): dimensionamento e funcionalidade na produção do mercado imobiliário. 2017. Memorial de Dissertação (Mestrado) Programa de PósGraduação em Arquitetura e Urbanismo, Universidade Federal do Rio Grande do Norte. Natal, 2017.

MONT'ALVÃO, Cláudia. A ergonomia do ambiente construído no Brasil. In: MONT'ALVÃO, Cláudia; VILLAROUCO, Vilma. (Orgs). Um novo olhar para o projeto: a ergonomia no ambiente construído. Teresópolis, RJ: 2AB, 2011. p. 13-24.

MORAES, Anamaria de. Prefácio. In: MORAES, Anamaria de. (Org.). Ergodesign do ambiente construído e habitado: ambiente urbano, ambiente público, ambiente laboral. Rio de Janeiro: iUsEr, 2004. p. 7-15.

PANERO, Julius; ZELNIK, Martin. Dimensionamento humano para espaços interiores. Barcelona: Gustavo Gili, 2002.

TRAMONTANO, Marcelo. Novos modos de vida, novos espaços de morar: São Paulo, Paris, Tokyo. In: SEMINÁRIO DE HISTÓRIA DA CIDADE E DO URBANISMO, 4, 1996, Rio de Janeiro. Anais... Rio de Janeiro: UFRJ, 1996. p. 973-979.

TRAMONTANO, Marcelo; BENEVENTE, Varlete. [Re]Programas: as e-pesquisas nomads sobre comportamentos \& espaços de morar. In: CONFERÊNCIA LATINO-AMERICANA DE CONSTRUÇÃO SUSTENTÁVEL, ENCONTRO NACIONAL DE TECNOLOGIA DO AMBIENTE CONSTRUÍDO, 10,

2004, São Paulo. Anais... São Paulo: ANTAC, 2004.

VERÍSSIMO, Francisco S.; BITTAR, William S. M. 500 Anos da Casa no Brasil. Rio de Janeiro: Ediouro, 1999.

VILLAROUCO, Vilma. Tratando de ambientes ergonomicamente adequados: seriam ergoambientes? In: MONT'ALVÃO, Cláudia; VILLAROUCO, Vilma. (Orgs). Um novo olhar para o projeto: a ergonomia no ambiente construído. Teresópolis, RJ: 2AB, 2011. 